Imalat Teknolojileri ve Uygulamalar

Cilt: 2, No: 2, 2021 (30-40)

Araștırma Makalesi

e-ISSN: $2717-7475$
Manufacturing Technologies and Applications

Vol: 2, Issue: 2, 2021 (30-40)

Research Article

e-ISSN: $2717-7475$

\title{
Cr(VI) elektrokaplama banyolarının Cr(III) banyolarına dönüştürülmesinde etkin faktörlerin belirlenmesi
}

\author{
Ramazan Katırc1 ${ }^{1 *(D)}$, Abdulaziz Altınsarı ${ }^{2}$ (D) \\ ${ }^{I}$ Sivas Bilim ve Teknoloji Üniversitesi, Metalurji ve Malzeme Mühendisliği, Sivas, Türkiye, \\ ${ }^{2}$ Karabük Üniversitesi, Metalurji ve Malzeme Mühendisliği, Karabük, Türkiye
}

MAKALE BILLGISI

Alınma: 10.06 .2021

Kabul: 24.08.2021

Anahtar Kelimeler:

Cr(III) elektrokaplama

Cr(VI) elektrokaplama

banyosu

Kimyasal dönüşüm

Metal kaplama

\section{ÖZET}

Krom (Cr) kaplama dekoratif ve fonksiyonel amaçlı yaygın biçimde kullanılmaktadır. Yüksek sertlik, parlak görünüm, mükemmel aşınma ve korozyon direncine sahiptirler. $\mathrm{Cr}(\mathrm{VI})$ toksik bir malzemedir. $\mathrm{Bu}$ yüzden $\mathrm{Cr}(\mathrm{VI})$ banyolarından elde edilen $\mathrm{Cr}$ kaplama, çalışan sağlığı ve çevre açısından büyük risk oluşturmaktadır. Bu yüzden benzer kalite ve özelliklere sahip, ayrıca toksik ve çevreye zararlı etkisi olmayan Cr(III) banyoları, Cr(VI)'ya iyi bir alternatiftir. Daha az zararlı ve kolay arıtılabilir olması tercih sebebidir. $\mathrm{Bu}$ makalenin amac1, mevcut $\mathrm{Cr}(\mathrm{VI})$ banyolarının uygun maliyetle $\mathrm{Cr}$ (III) banyosuna dönüştürülerek doğaya deşarjının önlenmesidir. Bunu sağlamak için 3 farklı firmadan $\mathrm{Cr}(\mathrm{VI})$ kaplama banyosu toplanmış, kimyasal dönüşüm yöntemli ile Cr(III) kaplama banyosuna dönüştürme çalışması yapılmıștır. Dönüşüm sırasında Cr kaplamanın kalitesini etkileyen önemli faktörleri belirlemek için deneysel tasarım metodolojileri uygulanmıştır. Ana faktörlerin etkilerini ve etkileşimlerini belirlemek ve dönüşüm sürecini optimize etmek için $1 / 2$ kesirli faktöriyel deney tasarım metodu kullanılmıştır. Sonuçlar istatistiksel olarak değerlendirilmiş ve optimum dönüşüm parametreleri belirlenmiştir. İstatistiksel değerlendirme sonucunda girişkenliğe etki eden en önemli parametrenin kömürleme pH'1 olduğu gözlenmiştir. Bazik ortamda aktif kömürün ortamdaki safsılılıları daha iyi uzaklaştırdığı tespit edilmiştir. Parlaklığa etki eden en önemli parametresinin ise $\mathrm{Cr}$ (III) kompleksleşme reaksiyon süresi olduğu bulunmuştur.

\section{Determination of effective factors in conversion of $\mathrm{Cr}(\mathrm{VI})$ electroplating baths to $\mathrm{Cr}$ (III) baths}

\section{ARTICLE INFO}

Received: 10.06 .2021

Accepted: 24.08 .2021

Keywords:

Cr(III) electroplating

$\mathrm{Cr}(\mathrm{VI})$ electroplating bath

Chemical conversion

Metal plating

\begin{abstract}
Chrome $(\mathrm{Cr})$ plating is widely used for decorative and functional purposes. They have high hardness, bright appearance, excellent wear and corrosion resistance. $\mathrm{Cr}(\mathrm{VI})$ is a toxic material. Therefore, $\mathrm{Cr}$ coating obtained from $\mathrm{Cr}(\mathrm{VI})$ baths has a great risk in terms of employee health and the environment. Therefore, $\mathrm{Cr}(\mathrm{III})$ baths, which have similar quality and properties, and do not have toxic and harmful effects to the environment, are a good alternative to $\mathrm{Cr}(\mathrm{VI})$. It is preferred because it is less harmful and easily purified.The aim of this study is to convert existing $\mathrm{Cr}(\mathrm{VI})$ baths into $\mathrm{Cr}$ (III) baths at an affordable cost and to prevent their discharge into nature. In order to achieve this, $\mathrm{Cr}(\mathrm{VI})$ plating bath was collected from 3 different companies, and chemical conversion process was performed to convert it into $\mathrm{Cr}(\mathrm{III})$ plating bath. Experimental design methodologies were applied to identify the important factors affecting the quality of the $\mathrm{Cr}$ coating during conversion. The $1 / 2$ fractional factorial experimental design method was used to determine the effects and interactions of the main factors and to optimize the conversion process. The results were evaluated statistically and optimum conversion parameters were acquired. As a result of the statistical evaluation, it was observed that the most important parameter affecting the throwing power was the the $\mathrm{pH}$ of activated carbon treatment. It has been determined that activated carbon in alkaline medium removes impurities better in the medium. It was found that the most important parameter affecting the brightness was the $\operatorname{Cr}(\mathrm{III})$ complexation reaction time.
\end{abstract}




\section{GİRIŞ (INTRODUCTION)}

Krom kaplama ticari olarak tüm dünyada yaygın olarak kullanılmaktadır. Hem parlaklığı hem de korozyon direnci yüksektir. Ayrıca aşınmaya karşıda dirençlidir [1,2]. Krom kaplama (Sert krom, dekoratif krom) maalesef geleneksel $\mathrm{Cr}(\mathrm{VI})$ solüsyonlarından elde edilmektedir. Bilindiği gibi $\mathrm{Cr}(\mathrm{VI})$ banyoları hem toksik hem de kanserojendir [3]. Ciddi sağlık problemlerine sebep olması ve çevreye zarar vermesi nedeniyle ABD, Japonya, Avrupa gibi ülkelerde kullanımı sınırlandırılmıştır [4,5]. $\mathrm{Cr}$ (III) elektrokaplama banyolarından elde edilen krom kaplamalar $\mathrm{Cr}(\mathrm{VI})$ dan elde edilen kaplamalara önemli bir alternatiftir. Bu yüzden $\mathrm{Cr}$ (III) kaplamaların yaygınlaştırılması insan sağlığı ve çevre kirliliği açısından büyük önem arz etmektedir [6]. Bunu yapabilmek içinde $\mathrm{Cr}(\mathrm{III})$ kaplamanın hem ekonomik hem de işletim güçlüğü açısından uygun hale getirilmesi gerekiyor.

$\mathrm{Cr}$ (III) kaplama, $\mathrm{Cr}$ (VI)'ya kıyasla hem pahalı hem de işletimi daha zor bir prosestir. $\mathrm{Cr}$ (III) banyosu, sulu çözeltisinde doğrudan kaplanmaz. Çünkü Cr(III) iyonları kinetik olarak stabildir ve su ile $\left[\mathrm{Cr}\left(\mathrm{H}_{2} \mathrm{O}\right)_{6}\right]^{+3}$ kompleksini oluşturur [7,8]. $\mathrm{Cr}$ (III) iyonlarının indirgenme potansiyelini düşürmek için, formik asit, üre, asetat, glisin gibi kompleksleyici ajanların kullanılması gereklidir [9]. Kompleks ligandlar, Cr (III) iyonları ve su molekülleri arasındaki mesafeyi arttırır ve Cr(III)$\mathrm{H}_{2} \mathrm{O}$ kararlılığını bozar. Böylece $\mathrm{Cr}$ (III) iyonlarının katoda yaklaşmasını ve daha kolay indirgenmesini sağlar [10]. Organik kompleksler aynı zamanda, kaplamanın yüzey morfolojisinin geliştirilmesinde de önemli bir role sahiptir [8]. Ayrıca, Cr(III)'ün indirgenmesini zorlaştıran ikinci faktör, katottaki hidrojen gazı çıkışıdır. Suyun indirgenme potansiyeli $\left[\mathrm{Cr}_{(}\left(\mathrm{H}_{2} \mathrm{O}\right)_{6}\right]^{+3}$ den düşük olduğundan, katotta Cr kaplamasını önleyen aşırı hidrojen oluşumu gerçekleşir [1].

$\mathrm{Cr}(\mathrm{VI})$ kaplama banyosu bir veya daha fazla katalizör içermektedir. Cr (VI) banyolarında yaygın olarak kullanılan katalizörler sülfat ve florür içerikli bileşiklerdir. Florür katalizörü genellikle ortama silikaflorür $\left(\mathrm{SiF}_{6}{ }^{-2}\right)$ olarak eklenir. Sülfürik asit ve/veya sodyum sülfat, sülfat kaynağı olarak kullanılır [11,12]. Cr kaplama banyosunda kurşun, anot olarak kullanılır. Kurşun ağır metaldir, insan sağlığ 1 ve çevre kirliliği açısından tehlikelidir [13].

$\mathrm{Cr}(\mathrm{VI})$ banyolarını $\mathrm{Cr}(\mathrm{III})$ banyolarına, kimyasal dönüşüm prosesi ile dönüştürmek mümkündür. $\mathrm{Bu}$ şekilde $\mathrm{Cr}$ (III) kaplamanın işletim maliyeti düşürülmüş ve daha ekonomik $\mathrm{Cr}$ (III) elektrokaplama banyosu elde edilmiş olur. Katırcı ve ekibi 2020 yılında $\mathrm{Cr}(\mathrm{VI})->\mathrm{Cr}$ (III) dönüşümünü sağlayan proses geliştirmiştir. Bu çalışmada kimyasal dönüşüm prosesinde etkin faktörleri (aktif karbon, pH, kaynama süresi ve süzme işlemi) incelemişler ve kaplamanın parlaklığına, girişkenliğine, rengine ve siyahlığa etkileri araştırılmıştır. Ancak ön işlem aşamaları anlatılmamıştır. Ayrıca ön işlem aşamasında araştırılan faktörler ve sonuçları makalede yayınlanmamıştır [14]. Bu çalışmanın amacı bu sonuçları yayınlamak ve sektörel bilincin arttırılmasına katkı sağlamaktır. Böylece hem Cr(VI) kaplama banyosu atığının çevreye atılmasını önleyecek bilgi birikimi hem de mevcut $\mathrm{Cr}$ (VI) banyolarının $\mathrm{Cr}$ (III) elektrokaplama banyolarına dönüşümü için gerekli deneyim sektöre kazandırılmış olacaktır.

\section{MATERYAL VE YÖNTEM (MATERIAL AND METHOD)}

Cr(VI)'yı Cr(III)'e indirgeme aşaması sodyum metabisülfitle yapılmıştır. Atık Cr(VI) banyolarında metalik safsızlıkları uzaklaştırmak için alkali ortamda kimyasal yöntemle çöktürme işlemi uygulanmıştır. Banyo pH'ları sodyum hidroksit $(\mathrm{NaOH})$ ve sülfürik asit $\left(\mathrm{H}_{2} \mathrm{SO}_{4}\right)$ ile ayarlanmıştır. Kimysal dönüşüm prosesi aşamasında kullanılan kimyasallar analitik kalitededir. Elektrokaplama işlemlerinde Hull-cell kullanılmıştır ve $55^{\circ} \mathrm{C}$ de $2 \mathrm{~A} 5 \mathrm{dk}$ süreyle krom kaplama gerçekleştirilmiştir. Anot olarak grafit kullanılmıştır. Elektrolitik kaplama sonrası parlaklık ölçümleri MITECH TECHNOLOGY MG-268 model glossmetre cihazıyla yapılmıştır. Deney planları ve istatistiksel değerlendirmeler MINITAB 15 programı ile yapılmıştır. Standart bakır plaka üzerine yapılan krom kaplama tüm yüzeyi kaplamamaktadır (Şekil 1). Yüksek akım yoğunluğundan düşük akım yoğunluğuna doğru kaplama kalınlığı azalmaktadır. Düşük akım yoğunluğuna doğru yaklaşık 1-5 cm arasında kaplama almayan bölge oluşmaktadır. Kaplama almayan bölge cetvelle ölçülmüş ve girişkenlik değeri olarak belirlenmiştir. Burada en düşük değer en iyiyi en yüksek 
değer ise en kötüyü temsil etmektedir. Değerlendirme ölçütü cetvelle ölçülen miktardır. Birimi santimetre $(\mathrm{cm})$ dir.

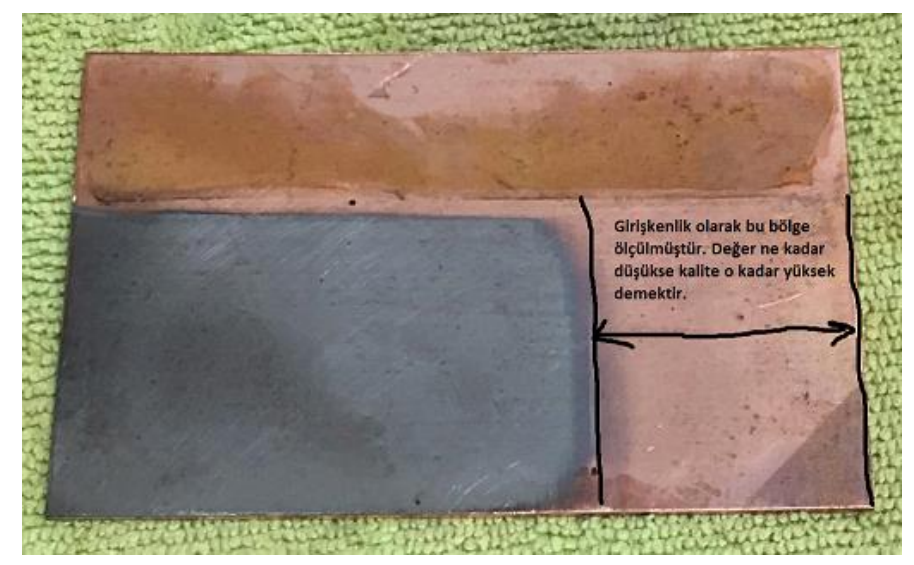

Şekil 1. Plakaların girişkenlik değerlerinin ölçümü (Measurement of the throwing power of the plates)

$\mathrm{Cr}(\mathrm{VI})$ banyosunun $\mathrm{Cr}(\mathrm{III})$ banyosuna dönüştürülmesi için iki aşama çok önemlidir. Bunlardan birincisi Cr(VI)'nın Cr(III)'e indirgenmesi için uygun kimyasalın seçilmesi, ikincisi ise çalışma sürecinde $\mathrm{Cr}(\mathrm{VI})$ banyosunda çözünen metalik ve organik safsızlıkların ortamdan uzaklaştırılmasıdır. Cr(VI)'nın Cr(III)'e indirgeme aşamasında kullanılacak kimyasalın seçimi için literatür araştırmasından 3 kimyasal belirlenmiştir. Bunlar; hidrojen peroksit, metanol ve sodyum metabisülfittir. Full faktöriyel deney planları oluşturulmadan önce, klasik yöntemle $\mathrm{Cr}(\mathrm{VI})$ 'nın $\mathrm{Cr}$ (III)'e indirgenme çalışmaları ve safsızların ortamdan uzaklaştırılması çalışmaları yapılmıştır.

İlk çalışmamızda hidrojen peroksit indirgeyici olarak kullanılmıştır. Ancak banyoda köpürmeler ve taşmalar meydana gelmiştir. Bu yüzden hidrojen peroksit kullanımından vazgeçilmiştir. İkinci olarak metanol indirgeyici kullanılmıştır. İndirgeme süresi 1 günden fazla sürdüğünden endüstride uygulanabilir bulunmamıştır. Üçüncü olarak literatürden metabisülfit kimyasalı tespit edilmiş ve indirgeyici olarak çalışmamıza dahil edilmiştir. İndirgemenin hızlı gerçekleşmesi ve banyoda herhangi bir taşma meydana getirmemesi sebebiyle bu kimyasal tüm çalışmamız boyunca kullanılmıştır. Ayrıca sodyum metabisülfitin banyoda yabancı atık bırakmaması da önemli bir avantajdır.

Krom banyosundan metalik safsızlıkların giderilmesi için selektif kaplama (dummy plating) ve çöktürme denemeleri yapılmıştır. Selektif kaplama hem uygulaması kolay hem de daha ucuz olduğu için öncelikli olarak çalışılmıştır. Selektif kaplama 1 amper akım 2 saat süreyle uygulanmıştır. Selektif kaplama işlemi sonrasında, Cr(III) kaplama banyosunda herhangi bir kaplama gözlenmemiştir (Şekil 2). Bu yüzden metalik safsızlıkları uzaklaştırmak için banyoda yüksek pH'da çöktürme işlemi yapılmıştır. Bunun için sodyum hidroksit ile $\mathrm{pH}$ 12'ye yükseltilmiş ve oluşan çökelek (bakır, nikel, demir) süzgeç kağıdında süzülmüştür (Şekil 3). Süzme işleminden sonra indirgeme aşaması yapılmış ve gerekli kimyasalların ilavesinden sonra $\mathrm{Cr}$ (III) banyosu oluşturulmuştur. $\mathrm{Bu}$ işlem sonrası yapılan kaplamada $\mathrm{Cr}$ (III) kaplamanın yüzeyi önemli derecede iyileşmiştir (Şekil 4). Tüm krom kaplamalar bakır plaka üzerine yapılmıştır. 


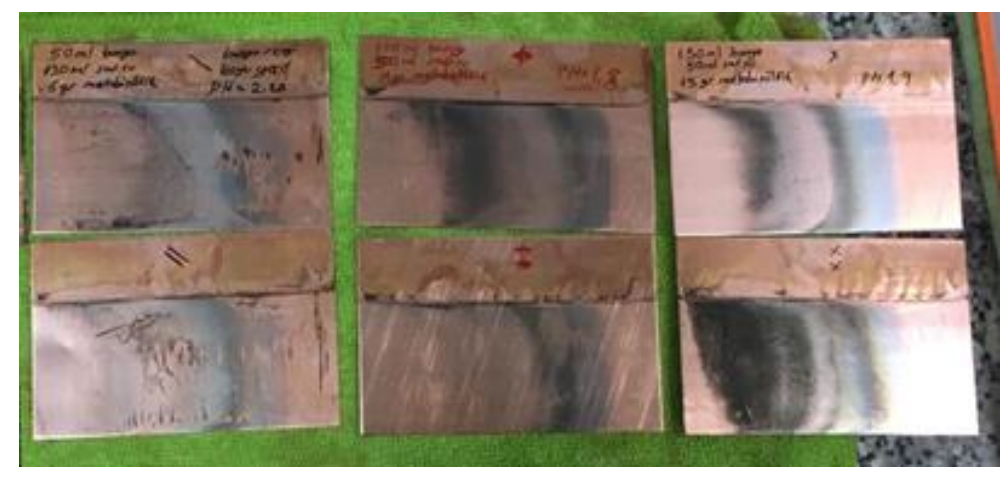

Şekil 2. Selektif kaplama sonrası kaplama (Coating after the dummy plating)

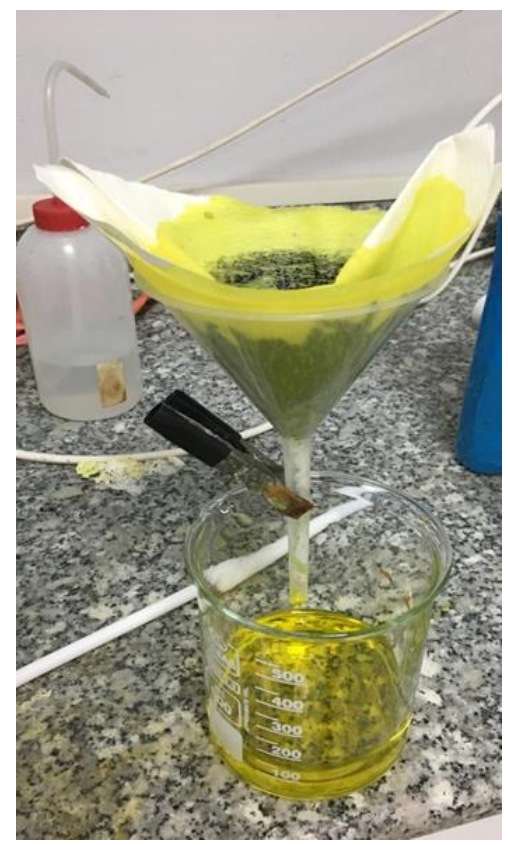

Şekil 3. Çöktürme işlemi için kurulan düzenek (The set up for the precipitation process)

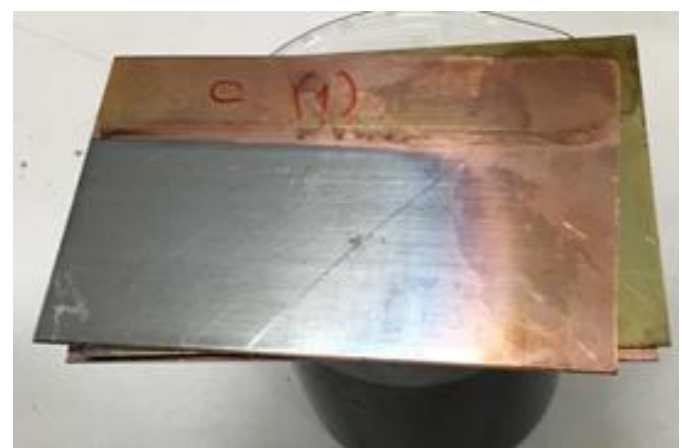

Şekil 4. Metalik safsızlıkları çöktürme işleminden sonraki kaplama (Coating after the precipitation of metallic impurities)

Ön çalışmalarda hangi kimyasalın $\mathrm{Cr}(\mathrm{VI})$ 'yı $\mathrm{Cr}$ (III)'e indirgediği ve safsızlıkların hangi yöntemle en iyi şekilde uzaklaştırıldığı belirlendikten sonra, kimyasal dönüşüm prosesinde etkin parametrelerin belirlenmesi için iki seviyeli $1 \frac{1}{2}$ kesirli faktöriyel deney planları oluşturulmuştur. Ön deneysel çalışmalar ve literatür 1şı̆̆ında Şekil 5 'te belirtilen parametreler, bağımsız değişkenler olarak, girişkenlik ve parlaklık parametreleri ise kalite değişkeni olarak belirlenmiştir. Deneyler tek tekrarlı olarak gerçekleştirilmiştir. 


\section{DENEY PLANI}

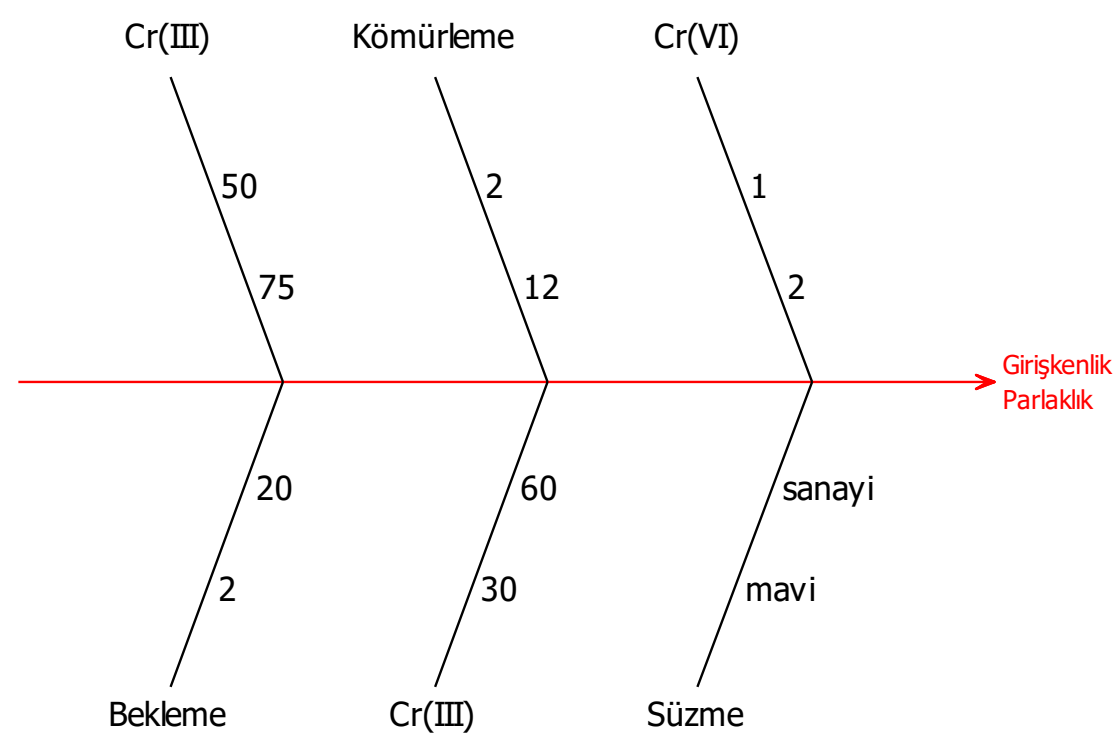

Şekil 5. Kalite değişkenleri (Girişkenlik, parlaklık) ve kaliteyi etkileyen bağımsız değişkenler, Kaynama Sıcaklığı (CrIII), Bekleme Süresi (saat), Kömürleme pH'1, Kaynama Süresi (Cr(III), dk), Cr(III) pH, Cr(VI) kaynatma süresi (saat), Süzme (Quality variables (throwing power, brightness) and independent variables affecting quality, Boiling Temperature (CrIII), Waiting Time (hour), Carbonizing pH, Boiling Time (Cr(III), min), $\mathrm{Cr}(\mathrm{III}) \mathrm{pH}, \mathrm{Cr}(\mathrm{VI})$ ) boiling time (hours), Filtering)

Farklı firmalardan toplanan $\mathrm{Cr}(\mathrm{VI})$ banyoları tek bir kapta toplanarak süzülmüştür. Süzme işleminden sonra $\mathrm{Cr}(\mathrm{VI})$ banyosundan organik safsızlıkları uzaklaştırmak için aktif kömürleme işlemi uygulanmıştır. Aktif kömür (toz) miktarı $4 \mathrm{~g} / \mathrm{L}$ olarak belirlenmiştir. Kömürleme işlemi 1 saat 60 santigrat derecede yapılmış, işlem sonucunda sanayi tipi süzgeç kağıdıyla süzme yapılarak aktif kömür ortamdan uzaklaştırılmıştır. Aktif kömürle saflaştırma işleminden sonra sanayi banyolarında, 50-100 g/L arasında $\mathrm{Cr}$ metali olması beklenmektedir. Bu yüzden bunların miktarını belirlemek için volumetrik yöntem metodu kullanılmıştır. Analiz sonunda Cr miktarı 75-85 g/L olarak ölçülmüştür. Uzun süreli çalışmalarda anotta $\mathrm{Cr}(\mathrm{VI})$ iyonları oluşmaktadır. Bunu önlemek için normalde $\mathrm{Ti} / \mathrm{IrO}_{2}$ kaplı anot kullanılmaktadır. Ancak kısa süreli kullanımlarda $\mathrm{Cr}(\mathrm{VI})$ oluşması beklenmemektedir. Bu yüzden Hull-hücrelerinde kaplamalar 2 amper 5 dakikada ve grafit anot kullanılmıştır.

Minitab programına 6 parametre değişken olarak girilmiştir. 6 parametrenin klasik deney yöntemine göre tüm olasılıkların çalışılması için 64 deney düzeneği kurulması gerekmektedir. Ancak 1/2 kesirli faktöriyel deney tasarımı yöntemi kullanılarak deney sayısı 32'ye düşürülmüştür. Oluşturulan deney planı Tablo 1 de sunulmuştur. Her bir satır deney aşamasında değiştirilen parametreleri göstermektedir. Toplam 32 adet hull-cell çalışması yapılmıştır. 
Tablo 1. 6 parametreli $1 \frac{1}{2}$ kesirli faktöriyel deney planı ( $1 \frac{1}{2}$ fractional factorial experiment plan with 6 parameters)

\begin{tabular}{|c|c|c|c|c|c|c|}
\hline $\begin{array}{l}\text { Deney } \\
\text { sırası }\end{array}$ & $\begin{array}{c}\text { Cr6- } \\
\text { kaynatma } \\
\text { süresi } \\
\text { (saat) } \\
\end{array}$ & $\begin{array}{c}\text { Süzgeç } \\
\text { kağıdı tipi }\end{array}$ & $\begin{array}{c}\text { Kömürleme } \\
\text { (pH) }\end{array}$ & $\begin{array}{c}\text { Kaynama } \\
\text { Süresi, dk } \\
\text { (CrIII) }\end{array}$ & $\begin{array}{c}\text { Kaynama } \\
\text { Sicaklığı, } \\
{ }^{0} \mathrm{C} \text { (CrIII) }\end{array}$ & $\begin{array}{c}\text { Bekleme } \\
\text { Süresi } \\
\text { (saat) }\end{array}$ \\
\hline 1 & 1 & mavi & 2 & 30 & 50 & 2 \\
\hline 2 & 2 & mavi & 2 & 30 & 50 & 20 \\
\hline 3 & 1 & sanayi & 2 & 30 & 50 & 20 \\
\hline 4 & 2 & sanayi & 2 & 30 & 50 & 2 \\
\hline 5 & 1 & mavi & 12 & 30 & 50 & 20 \\
\hline 6 & 2 & mavi & 12 & 30 & 50 & 2 \\
\hline 7 & 1 & sanayi & 12 & 30 & 50 & 2 \\
\hline 8 & 2 & sanayi & 12 & 30 & 50 & 20 \\
\hline 9 & 1 & mavi & 2 & 60 & 50 & 20 \\
\hline 10 & 2 & mavi & 2 & 60 & 50 & 2 \\
\hline 11 & 1 & sanayi & 2 & 60 & 50 & 2 \\
\hline 12 & 2 & sanayi & 2 & 60 & 50 & 20 \\
\hline 13 & 1 & mavi & 12 & 60 & 50 & 2 \\
\hline 14 & 2 & mavi & 12 & 60 & 50 & 20 \\
\hline 15 & 1 & sanayi & 12 & 60 & 50 & 20 \\
\hline 16 & 2 & sanayi & 12 & 60 & 50 & 2 \\
\hline 17 & 1 & mavi & 2 & 30 & 75 & 20 \\
\hline 18 & 2 & mavi & 2 & 30 & 75 & 2 \\
\hline 19 & 1 & sanayi & 2 & 30 & 75 & 2 \\
\hline 20 & 2 & sanayi & 2 & 30 & 75 & 20 \\
\hline 21 & 1 & mavi & 12 & 30 & 75 & 2 \\
\hline 22 & 2 & mavi & 12 & 30 & 75 & 20 \\
\hline 23 & 1 & sanayi & 12 & 30 & 75 & 20 \\
\hline 24 & 2 & sanayi & 12 & 30 & 75 & 2 \\
\hline 25 & 1 & mavi & 2 & 60 & 75 & 2 \\
\hline 26 & 2 & mavi & 2 & 60 & 75 & 20 \\
\hline 27 & 1 & sanayi & 2 & 60 & 75 & 20 \\
\hline 28 & 2 & sanayi & 2 & 60 & 75 & 2 \\
\hline 29 & 1 & mavi & 12 & 60 & 75 & 20 \\
\hline 30 & 2 & mavi & 12 & 60 & 75 & 2 \\
\hline 31 & 1 & sanayi & 12 & 60 & 75 & 2 \\
\hline 32 & 2 & sanayi & 12 & 60 & 75 & 20 \\
\hline
\end{tabular}

32 adet hull-cell çalışması sonucunda girişkenlik ve parlaklık parametreleri ölçülmüştür. İndirgeme ve saflaştırma aşamaları tamamlandıktan sonra, banyo içine Tablo 2 deki miktarlarda sakarin, malonik asit, sodyum sülfat ve borik asit ilaveleri yapılmış ve pH değeri ayarlanarak $\mathrm{Cr}(\mathrm{III})$ banyosu oluşturulmuştur [15]. Kompleksleşme oluşumu için $\mathrm{Cr}$ (III) banyosu iki farklı sürelerde (30 ve $60 \mathrm{dk}$ ) kaynatılmıştır. Bu şekilde Tablo 2'deki şartlarda 32 banyo oluşturulmuş ve her birinin 2 A $5 \mathrm{dk}$ süreyle hull-cell plakaları çekilmiştir. 
Tablo 2. Cr(III) banyosu formülü (Cr(III) bath formula)

\begin{tabular}{cc}
\hline KIMYASAL & MiKTAR \\
\hline Krom Sülfat & $10 \mathrm{~g} / \mathrm{L}$ \\
Sakarin & $20 \mathrm{~g} / \mathrm{L}$ \\
Malonik asit & $3 \mathrm{~g} / \mathrm{L}$ \\
$\mathbf{p H}$ & 3.5 \\
$\mathbf{N a}_{2} \mathbf{S O}_{4}$ & $150 \mathrm{~g} / \mathrm{L}$ \\
$\mathbf{H}_{3} \mathbf{B O}_{3}$ & $60 \mathrm{~g} / \mathrm{L}$ \\
$\mathbf{E H S}$ & $1 \mathrm{~mL} / \mathrm{L}$ \\
\hline
\end{tabular}

\section{SONUÇLAR VE TARTIŞMA (RESULTS AND DISCUSSION)}

Tablo 1'deki deneyler yapıldıktan sonra, ölçüm sonuçları Minitab programına girilmiştir. Minitab programında bağımsız değişkenlerin bağımlı değişkenler üzerindeki etkileri tablolar halinde çıkarılmıştır. Sonuçlar Şekil 6-9 da sunulmuştur. Bağımsız değişken olarak $\mathrm{Cr}(\mathrm{VI})$ kaynatma süresi, süzme (mavi veya sanayi tipi süzgeç kağıdı), aktif kömürleme pH'1, Cr(III) banyosu kaynama süresi, $\mathrm{Cr}$ (III) banyosu kaynama sıcaklığı, $\mathrm{Cr}$ (III) banyosu oluşturulduktan sonra bekleme süresi belirlenmiş ve bunların girişkenlik ve parlaklığa etkileri araştırılmıştır.

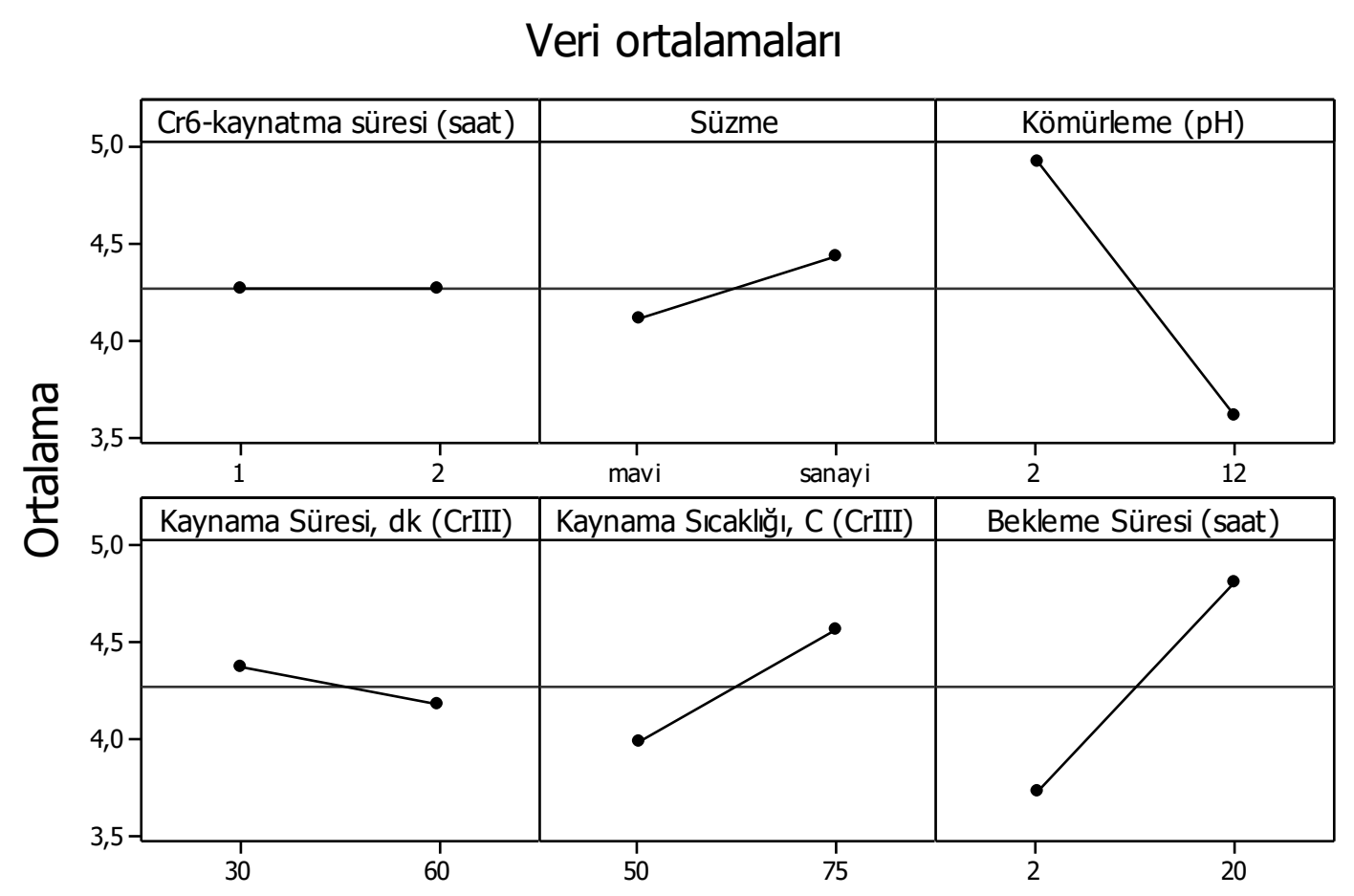

Şekil 6. Ana faktörlerin girişkenliğe etkisi (dik eksen girişkenlik miktarını göstermektedir. En düşük en iyidir) (The effect of main factors on throwing power (the vertical axis shows the amount of throwing power. The lowest is the best))

Şekil 6 incelendiğinde $\mathrm{Cr}(\mathrm{III})$ kaplamanın girişkenliğine en fazla etki eden parametrelerin kömürleme pH’1 ve bekleme süresidir. Bazik ortamda yapılan kömürlemenin $\operatorname{Cr}($ III) kaplamaya olumlu yönde katkı yaptığı görülmektedir. Cr(III) banyosu oluşturulduktan sonra, kaplama öncesi bekleme süresi $\mathrm{Cr}(\mathrm{III})$ kaplamanın girişkenliğini azalttığı görülmektedir. Bu bize banyonun kararlılığının zamanla düştüğünü göstermektedir. Genel olarak şekil 6 yorumlandığında $\mathrm{Cr}(\mathrm{VI})$ 
kaynatma süresinin, girişkenliğe bir etki etmediği, süzme işlemi sanayi tip süzgeç ile yapıldığında girişkenliğgi düşürdüğü, aktif kömürleme bazik ortamda $(\mathrm{pH}=12)$ yapıldığında girişkenliğin arttığı, kaynatma süresi 60 dakika olduğunda girişkenliğin arttığı, kaynama sıcaklığ1 yükseldikçe girişkenliğin düştüğü, bekleme süresi uzadığında girişkenliğin düştüğü görülmektedir.

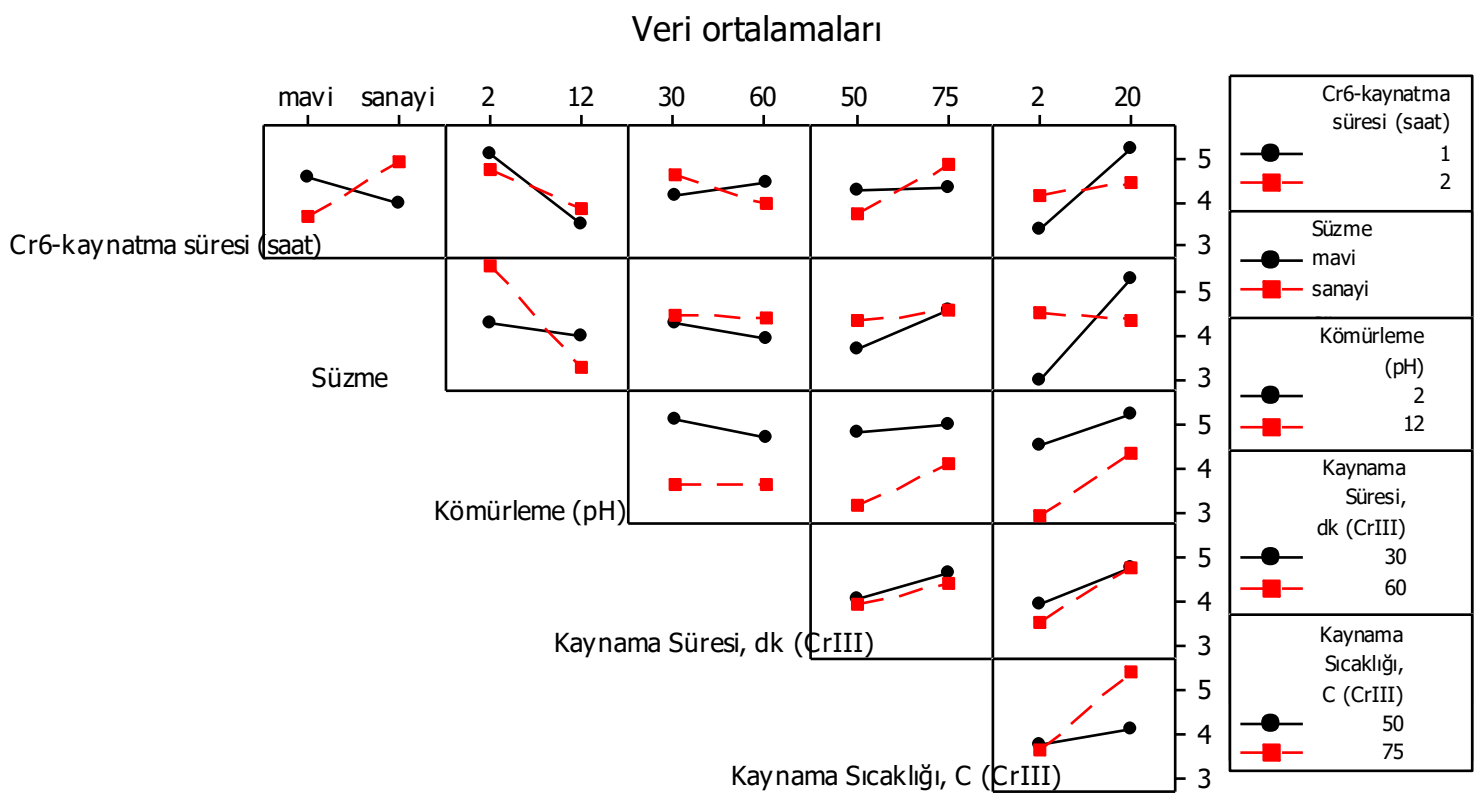

Bekleme Süresi (saat)

Şekil 7. Faktörlerin etkileşimleri (Dikey eksen girişkenliği, yatay eksen faktör değişimlerini göstermektedir) (Interactions of factors (Vertical axis shows throwing power, horizontal axis shows factor changes)).

Şekil 7 incelendiğinde Cr(VI) kaynatma süresinin banyonun stabilitesini artırdığı gözlenmiştir. Yani $\mathrm{Cr}$ (III) banyosu hazırlandıktan sonra bekleme süresi artsa bile $\mathrm{Cr}$ kaplamanın girişkenliği düşmemektedir. Kömürleme işlemi yüksek pH'da yapıldığında banyonun stabilitesi önemli derecede artmaktadır. Aynı şekilde süzme işlemi için sanayi kalite süzgeç kâğıdı kullanıldığında da banyo stabilitesi artmaktadır. Bunun sebebi mavi bant süzgeç kâğıdı banyoda faydalı kimyasalları tutuyor olabilir. 


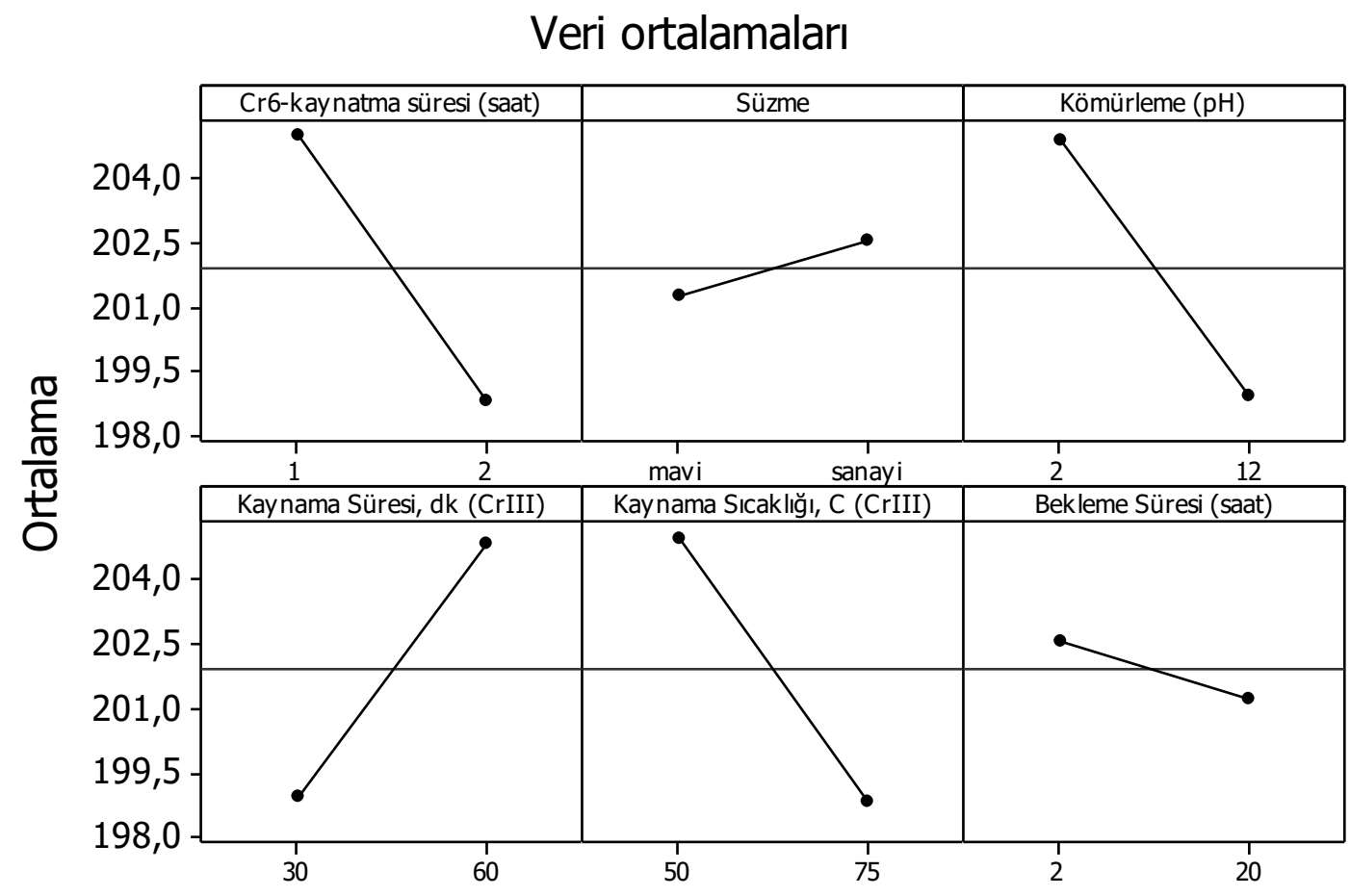

Şekil 8. Faktörlerin parlaklığa etkileri (Dikey eksen gloss cinsinden parlaklık değerini göstermektedir) (Effects of factors on the brightness (Vertical axis shows brightness value as gloss))

Veri ortalamaları

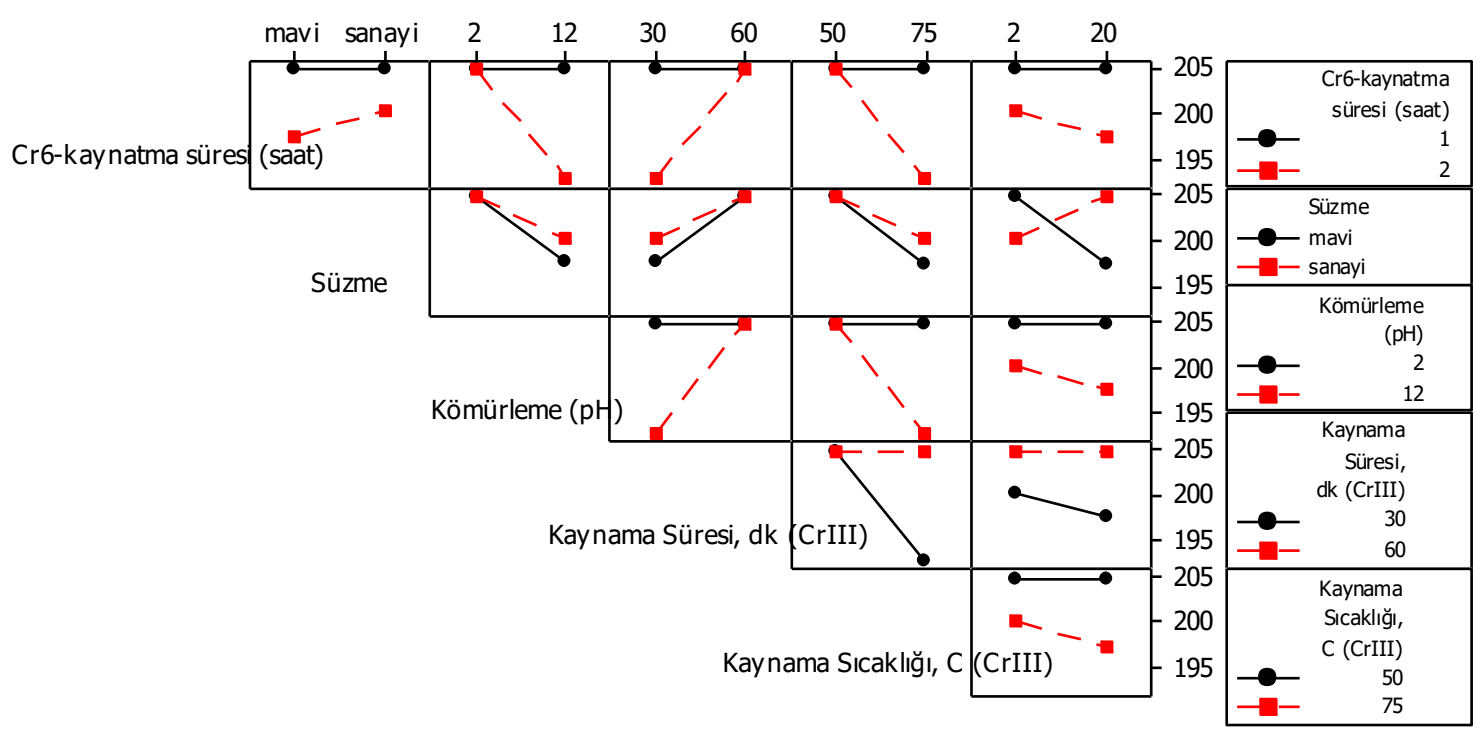

Bekleme Süresi (saat)

Şekil 9. Parlaklığa etki eden faktörlerin ikili etkileşimleri (Dikey eksen gloss cinsingen parlaklık değerini göstermektedir) (Bilateral interactions of the factors affecting the brightness (Vertical axis shows the brightness as gloss))

Şekil 8'de, temel değişkenlerin parlaklığa etkileri gösterilmiştir. Parlaklık ölçümleri üniversal değer olan $60^{\circ}$ de yapılmıştır. Parlaklığın artışına en yüksek pozitif etki yapan parametre $\mathrm{Cr}(\mathrm{III})$ 
kompleksleme (kaynama süresi (CrIII)) süresidir. Kompleksleme süresi 60 dakika olduğunda maksimum parlaklık elde edilmektedir. Diğer parametrelerin parlaklığı azaltıcı etki yapmıştır.

Şekil 9, Cr(VI) kaynatma süresinin 1 saat ve kömürleme pH'ının 2 olduğunda banyo stabilitesinin önemli derecede arttığını göstermektedir. Diğer parametrelerin bozucu etkisi düşmektedir. Maksimum girişkenlik ve parlaklık için optimum değerler Tablo 3 de gösterilmiştir. Optimum girişkenlik ve parlaklık için, $\mathrm{pH}$ hariç diğer parametreler aynıdır. Yüksek girişkenlik için kömürleme pH'ının 12 de tutulması gerekirken, yüksek parlaklık için $\mathrm{pH} 2$ de tutulması gerekmektedir. Yüksek parlaklık ve girişkenlik istenen bir durumdur. Bu yüzden bu iki şartında aynı anda sağlanabilmesi için optimum şartların oluşturulması önemlidir.

Tablo 3. Optimum girişkenlik ve parlaklık için, $\mathrm{Cr}$ (VI) banyosunun $\mathrm{Cr}$ (III) banyosuna dönüştürme şartları (Conditions for conversion of a $\mathrm{Cr}(\mathrm{VI})$ bath to a $\mathrm{Cr}(\mathrm{III})$ bath for optimum throwing power and brightness)

\begin{tabular}{lcc}
\hline & GİRíşKENLIK & PARLAKLIK \\
\hline Cr(VI) Kaynatma Süresi & 1 saat & 1 saat \\
Süzme & Mavi Tip Süzgeç & Mavi Tip Süzgeç \\
Kömürleme Ph & 12 (Bazik) & 2 (Asidik) \\
Cr(III) Kaynama Süresi & $60 \mathrm{dk}$ & $60 \mathrm{dk}$ \\
Kaynama Sıcaklığı & $50^{\circ}$ & $50^{\circ}$ \\
Bekleme Süresi & 2 saat & 2 saat \\
\hline
\end{tabular}

Sanayiden elde edilen $\mathrm{Cr}(\mathrm{VI})$ banyolarının içeriğinin tam olarak çözümlenebilmesi mümkün değildir. $\mathrm{Bu}$ yüzden süzme, kömürleme gibi parametrelerin banyo içinde neleri değiştirdiği tam olarak tespit edilememektedir. Bununla beraber, bu grafikler yardımıla kaliteye etkileri gözlemlenebilmektedir. Böylece kimyasal dönüşüm esnasında hangi parametrelerin, kalite değişkenlerine nasıl etki ettiği belirlenebilmektedir.

\section{SONUÇLAR (CONCLUSIONS)}

$\mathrm{Bu}$ çalışmada $\mathrm{Cr}$ (VI) banyosunun $\mathrm{Cr}$ (III) banyosuna dönüştürme aşamasında etkin faktörler araştırılmıştır. Dönüşümü etkileyen parametreler, kömürleme, $\mathrm{pH} 10$ da $\mathrm{Cr}(\mathrm{VI})$ banyosunu kaynatma, süzme, Cr (III) banyosunun kaynama süresi, kaynama sıcaklığı ve bekleme süresi belirlenmiştir. Bu parametrelerin etkisi kesirli faktöriyel deneysel tasarım yöntemi ile incelenmiştir. Girişkenlik ve parlaklık kalite değişkenleri olarak belirlenmiştir. Girişkenliğe etki eden en önemli parametrenin kömürleme pH'ı olduğu gözlenmiştir. Aktif kömürleme işlemi, kaplama banyosundan organik ve inorganik safsızlıkları uzaklaştırmak için kullanılmaktadır. Aktif kömür, safsızlıkları yüzeydeki gözenekleri sayesinde adsorplayabilmektedir. Bazik ortamda aktif kömürün ortamdaki safsızlıkları daha iyi uzaklaştırdığı tespit edilmiştir. Parlaklığa etki eden en önemli parametresinin ise $\mathrm{Cr}$ (III) kompleksleşme reaksiyon süresidir. Reaksiyonun tamamlanması için sıcaklığın $50{ }^{\circ} \mathrm{C}$ de ve sürenin $60 \mathrm{dk}$ 'dan az olmaması gerekmektedir. Ancak bu sonuçlar laboratuvar şartlarında elde edilmiştir. Sanayi koşullarında 1-2 tonluk banyolarda uzun süre çalıştığında nasıl tepki ile karşılaşılacağı bilinmemektedir. Bu ürünü sürdürülebilirliğini ölçmek için birkaç firmada 8-12 ay arası pilot çalışmaların yapılıp, farklı parçalar üzerinde $\mathrm{Cr}$ kaplama denemelerinin yapılması gerekmektedir.

Sonuç olarak Cr(VI) banyolarından Cr(III) banyosu elde etmenin mümkün olduğu gözlenmiştir. Böylece doğaya, toksik Cr(VI)'yı deşarj etmeden, kimyasal dönüşüm sonrası kromu tekrar kullanmak mümkündür. Cr(VI) insan sağlığı üzerinde de çok önemli mesleki hastalıklara sebep olmaktadır. Resmi OSHA (Occupational Safety and Health Administration) web sitesinden alınan veriye göre, $\mathrm{Cr}(\mathrm{VI})$ maruziyetinin göz tahrişi ve hasarı, solunum yolu tahrişi, böbrek hasarı, karaciğer hasarı, solunum kanseri, dişlerde aşınma ve renk değişikliği, burun tahrişi gibi solunum yolu hastalıklarına sebep olmaktadır. Cr(VI) banyosunda, aşırı hidrojen gazı çıkışı olduğu için 
Cr(VI) iyonlarını çalışma ortamına taşımaktadır. Çalışanlar iş ortamında solunum yoluyla bu iyonlara maruz kalmaktadır. Temas halinde ise alerjik hastalıklara sebep olmaktadır.

\section{TEŞEKKÜR (ACKNOWLEDGMENT)}

$\mathrm{Bu}$ proje Türkiye Bilimsel ve Teknik Araştırma Kurumu'nun (TÜBİTAK) desteği ile gerçekleştirilmiştir (Proje no: 217M240).

\section{KAYNAKLAR (REFERENCES)}

1. M. Ehasanul Haque, M. Asadul Hoque, M. Mayeedul Islam, M. Saidul Islam, C. Mohammad Mustafa, R. Carlos Cardoso Martins, Effect of Various Operating Effect of Various Operating Parameters on Trivalent Chromium Electroplating, J. Sci. Res. Reports Nucl. Mater. Auth. Cairo, Egypt. Panagopoulos Tak. Sakon. 13: 1-9, 2017.

2. K.-S. Nam, K.-H. Lee, S.-C. Kwon, D.Y. Lee, Y.-S. Song, Improved wear and corrosion resistance of chromium(III) plating by oxynitrocarburising and steam oxidation, Mater. Lett. 58: 3540-3544, 2004.

3. A. Liang, Y. Li, H. Liang, L. Ni, J. Zhang, A favorable chromium coating electrodeposited from Cr(III) electrolyte reveals anti-wear performance similar to conventional hard chromium, Mater. Lett. 189: 221224, 2017.

4. S. Ghaziof, K. Raeissi, M.A. Golozar, Improving the corrosion performance of $\mathrm{Cr}-\mathrm{C}$ amorphous coatings on steel substrate by modifying the steel surface preparation, Surf. Coatings Technol. 205: 2174-2183, 2010.

5. S. Surviliene, V. Jasulaitiene, O. Nivinskiene, A. Češuniene, Effect of hydrazine and hydroxylaminophosphate on chrome plating from trivalent electrolytes, Appl. Surf. Sci. 253: 6738-6743, 2007.

6. C.W. Liao, H. Bin Lee, K.H. Hou, S.Y. Jian, C.E. Lu, M. Der Ger, Characterization of the Cr-C/Si3N4 Composite Coatings Electroplated from a Trivalent Chromium Bath, Electrochim. Acta. 209: 244-253, 2016.

7. J.-Y. Lee, M. Kim, S.-C. Kwon, Effect of polyethylene glycol on electrochemically deposited trivalent chromium layers, Trans. Nonferrous Met. Soc. China. 19: 819-823, 2009.

8. N. Van Phuong, S.C. Kwon, J.Y. Lee, J.H. Lee, K.H. Lee, The effects of pH and polyethylene glycol on the $\mathrm{Cr}(\mathrm{III})$ solution chemistry and electrodeposition of chromium, Surf. Coatings Technol. 206: 4349 4355, 2012.

9. S. Surviliene, O. Nivinskiene, A. Češuniene, A. Selskis, Effect of Cr(III) solution chemistry on electrodeposition of chromium, J. Appl. Electrochem. 36: 649-654, 2006.

10.Z. Zeng, Y. Sun, J. Zhang, The electrochemical reduction mechanism of trivalent chromium in the presence of formic acid, Electrochem. Commun. 11: 331-334, 2009.

11.C. Fink, Process of electrodepositing chromium and of preparing baths therefor, Patent no:1,581,188, 1926.

12.C. Fink, Process of producing chromium-plated articles with mirrorlike scratch finish or the like surfaces, Patent no:1,802,463, 1931.

13.C.J. Abner Brenner, Polly Burkhead, Physical Properties of Electrodeposited Chromium, Part J. Res. Natl. Bur. Stand. Phys. 40: 31-59, 1948.

14.R. Katirci, A. Altınsar1, The conversion of the waste $\mathrm{Cr}(\mathrm{VI})$ electroplating bath to $\mathrm{Cr}(\mathrm{III})$ electroplating bath, Int. J. Environ. Sci. Technol. 17: 4205-4216, 2020.

15. R. Katırc1, A chrome coating from a trivalent chromium bath containing extremely low concentration of Cr3+ ions, Int. J. Surf. Sci. Eng. 10: 73-85, 2016. 